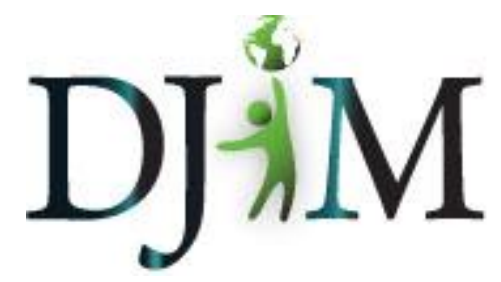

Volume 1 - Spring 2005 djim.management.dal.ca

\title{
Geospatial Information Management: spatial is still special
}

\begin{abstract}
About the Author(s): James Boxall, (BA, BEd, MA, MLIS Candidate, 2005), is currently completing a thesis on geospatial information policies in the Gulf of Maine. James is Curator of the Map Collection and Head of the newly established GIS Centre, His research interests, publications and presentations related to geographic information systems, information policies and spatial data infrastructures. He is a member of the Board of Directors for the Geomatics Association of Nova Scotia, a past President of the Association of Canadian Map Libraries and Archives, and previously on the Board for the Canadian Geospatial Data Infrastructure, and the Review Panel of the NSF funded Alexandria Geospatial Digital Library. James was recently elected to the Standing Committee on Geography and Map Libraries for IFLA, and to the editorial boards of the Journal of Map and Geography Libraries and "Coordinates" (ALA).
\end{abstract}

Candace Anderson (BA, Ad MGEO, MES Candidate, 2005), attended COGS and is currently completing a thesis on assessing biodiversity potential using expert systems in the School for Environmental Studies (SRES). Candace has also been working at the Map and Geospatial Collection (MAGIC) in the Killam library for the last three years. Candace is involved with a SLIS research project utilizing GIS to analyze historic print culture in Canada under the guidance of Dr. Fiona Black and Dr. Bertrum MacDonald. While primarily environmental, her research interests, publications and presentations relate to geographic information systems and other areas of geomatics. 


\section{Introduction}

This paper focuses on the interface between human information constructs and spatial decision making. But the discussion is also meant to speak to professionals in a variety of fields where information management is central; this can go beyond library and information studies because business, public administration and environmental management strategies rely heavily upon geospatial information and technologies (one need only think of how $80 \%$ of all information has some spatial element (Gore, 1998)). It is the contention here that spatial is so commonplace that it is no longer special.

Of importance, however, is both the policy issues associated with such distributed geolibraries and the effect of such practices on decision making, especially as it relates to public involvement This paper explores these questions, but it is also designed to provide a certain degree of prognostication based upon current developments in the geomatics field, a field which encompasses the geospatial information sector and the tools and science underlying distributed geospatial infrastructures (Groot and McLaughlin, 2000).

Geographically referenced information (GRI) can be any form of information which has attributes of location. Attributes can be postal codes, latitude and longitude, descriptive gazetteer or place names, or any Cartesian coordinate system, including a "z factor" of height and a "t" factor for time. Geographically referenced information is inherently broad in scope, but there is a sub-component of such GI which is becoming more common and increasingly associated with geographical information systems (GIS), namely geospatial information. The use of both GIS and geospatial information has long been a part of libraries (Soete, 1997; Boxall, 2004; Cobb, 1995; Cline, 1995; Millea, 2001), but it has been a very recent development where geospatial information has taken on a new form resulting from distributed geospatial information infrastructures (commonly called 'geolibraries': Goodchild, 1998).

A few brief definitions are needed at this point before any further exploration of geospatial information issues, trends, and prospects can take place. Foremost among these is geographic information systems (GIS). The ability to map and analyze geospatial information requires a technology designed to deal with spatiality. GIS is the technology that allows for the creation and manipulation of information that is geographic in orientation - as highlighted above. Place, space, and time define "spatial" and spatial applications in management systems as the underpinnings of GIS. "Spatial" need not be about the earth (geospatial), it could be the geographic description of a molecule or of the pattern of galaxies - all can be defined in a databases that use spatial descriptors and, therefore, be possible candidates for use in a GIS. 
Geomatics is a relatively new term to describe technologies and techniques which includes, but is not limited to GIS. Geomatics is a term that encompasses surveying, global positioning systems (GPS), geodesy, remote sensing (air photos and satellite imagery) and, of course, GIS. When geomatics is combined with cognitive research, ontological studies, and quantitative approaches we come to the definition of 'GIScience'. This theoretical field of spatial inquiry is what drives geomatics, which is the applied side that will also be discussed below.

\section{Geomatics in management}

Before discussing the role of geomatics in libraries, it is essential to give an overview of applications to other fields. These policy issues are germane to all fields in management; however, emphasis is placed more on libraries and information management. Geomatics in environmental management is perhaps one of the largest usages of both the theory and applied nature of geomatics and geospatial information. It takes little imagination to come to the realization that in order to adequately describe the natural environment, and to research the human-environment interfaces, requires a great deal of geospatial information. Environmental management has, in fact, been the driving force behind GIScience development until recently. Applications abound in the environmental fields: landscape ecology, coastal zone management, conservation priorities, green zone determination, habitat analysis, forest management, and a whole host of other applications are within the reach of environmental managers.

Geomatics in business is perhaps the fastest growing area of application. Recently there has been a greater focus in the geomatics community on the deployment of 'Location Based Services' (LBS). Such LBS combined with geomatics allows companies to achieve greater efficiency by fine tuning how, and where, services are delivered. One can think of a business sending advertisements delivered in real time via satellite, to the cell phone of a potential customer walking past their window. In order to 'target market' clients requires a sophisticated use of geomatics to locate the customer. Cell phones, as an example, use location as the prime means to access cell towers. Such locations can be 'back tracked' to find the customer. Privacy? One should take a closer look at cell phone agreements. There are also applications geared to the location of businesses and tracking patterns of use or customer bases. The location of a business should not be a case of 'best-guess', and so geomatics, accompanied with business location models creates a more accurate determination of location(s).

Geomatics in public administration takes the form of tools for administrators to better decide where services should be delivered. In addition, such technology and data means that a manager can better predict the spatial ramifications of decisions or policies or programs and 
governmental services. Are public services distributed in a manner which makes them accessible, and deliverable to a diverse range of the public? What is the marginal distance in which people are willing to seek a service? Are service points placed in the right location? If one takes on the additional factor of health care, then simple geospatial problems arise (but without simple solutions). Where are hospitals located? Where should they be located? What about emergency services? Distance and location are critical factors in determining location of health care services. The same could be said about schools. In that case, the key factor (beyond location) is the demographic make-up of the community. Mapping census data helps the administrator make a better choice when it is found that populations of school aged children are going down in one neighborhood but increasing in another. These questions are all spatial in nature. However, one area where geospatial information has been combined with information services provides us with an interesting case that also has implications for other managerial professions, and beyond, into the areas of information services.

\section{Geomatics in libraries}

In 1992, the Association of Research Libraries (US) began a program called the "GIS Literacy Project" which was sponsored by a number of private software and data providers. The project saw numerous US research libraries 'sign-on' in order to provide access to the tools and technologies associated with geospatial information. The project was 'transferred' to Canada in 1995 (Cline and Adler, 1995). The project was followed by many other efforts to see the expansion of services, from data provision to software instruction (Boxall, 2003). The real question was not if libraries would provide services or information, it was how such services would be provided (Fleet, 1998). This has ended up as a full blown examination of what the library is, what it is becoming, and why (Millea, 2001).

One need only look at the changes at Dalhousie to see the impact of developing geomatics related services and the increasing amount of geospatial data collected and made available. Dalhousie was one of the first to 'sign-on' to the GIS Literacy Project in Canada when it was instituted in 1995. The effect was minimal; 1995 saw the implementation of one computer, a donated colour printer, and a very limited amount of geospatial data which did not include any data from any governmental source in Canada. Staffing was only one, the curator. Ten years later the situation is radically different. Dalhousie has also seen, over the same period of time, a growth in the number of GIS courses and the demand for those courses (there are always more students than places of 'seats').

There are now over 140 computers in the Dalhousie Libraries Learning Commons with basic GIS software available. Additionally, there are five high-end computers with more processing power and hard drives, and additional software. Moreover, there is a GIS Centre established to provide services for all students, faculty and staff, as well as to administer a campus-wide 
GIS software license. Data supplies have grown exponentially. The Centre now provides access to all governmental data; federal, provincial and municipal for Nova Scotia, New Brunswick, Prince Edward Island, and extending to the country as a whole. Spatial information has also been provided from private sector suppliers at both regional and international scales.

The Centre has a full time staff complement of two, with plans to hire two more in 2005. Additionally, four graduate students are hired to provide GIS and map assistance. It should also be noted that while GIS was introduced in the library, the map collection (also a part of the GIS services) has grown by $50 \%$. GIS and maps have and continue to grow in tandem. The Centre is also developing a unique model of service. Besides providing basic access to data, software and hardware the GIS Centre provides basic instruction in software use, support to departments and faculty members in implementing GIS, data management services, cartography and GIS research design. Projects have ranged from whale sighting analysis, urban planning alternatives, and involvement with the history of Canadian print culture using GIS.

The Centre has become a service and research unit, and the three year mandate is to see the Centre expand more into the teaching and research areas, with the related need to seek external funds. Relative to other research libraries in Canada and the United States (the original GIS Literacy Project countries), Dalhousie has one of the top ten installations and services offered. Harvard, the University of California - Santa Barbara, University of Calgary, University of Virginia and the University of Connecticut likely the top five, with Dalhousie maybe being in 6th place, but that ranking is not official, just an educated (and hopeful) guess. The Centre is also not limited to GIS as it has access to and uses other geomatics technology and data. Ten years has seen a remarkable change, to say the least.

Now that we have seen how GIS has grown in libraries, and how the broad field of geomatics developed and is at play in the wider realm of management, it is a useful moment to shift gears' and delve into areas of concern to managers which are essentially information based. These areas of concern can be thought of as coming under the banner of information policy. From such a review we will be able to look at a few unique ways to deal with policy and information management, especially access and dissemination. Finally, we will return to the basic idea that spatial is special, especially in a very broad context of the information society.

\section{Information policy considerations}

The field of information policy is not limited to the purview of library and information professionals; it could be argued it is an area more for lawyers to tread as information policy agreements and documents are highly technical and legalistic. However, this discussion is limited to the management of geospatial information, and through the lens of information users 
and managers which reflect the backgrounds of the authors. It is important to place any policy discussion within a framework that guides the discussion (Rowlands, 2003) and may develop a more prescriptive approach, as opposed to the all-to-often descriptive study. This is also in keeping with some of the foundational ideas that have been put forward in the literature (Browne, 1997a and 1997b).

The authors are overt in their framework here in that their approach is normative and critical, with the concerned view that issues associated with geospatial information can be hidden in the 'information society' research, largely because those who speak to broad geospatial issues use 'grand views'. Obviously, there is also the argument that spatial is still special because of both the technical aspects and the specifics of policy (Georgiadou, \& Groot, 2002). Moreover, the idea of a political economy of access is present (Benkler, 2003; Birdsall, 2000) and it is due to the fact that it is pervasive in the literature of geospatial information. The authors contend that information managers need to be concerned with the technical and social issues with regard to accessing geospatial information. The use of geospatial information, and the issue of access so that use can happen, is of a more central concern for managers in fields that see information as an input rather than a throughput. Geospatial information, as described above, has the opportunity of being a process, not merely input of output.

\section{Geospatial information management}

Because geospatial information is inexorably tied to geomatics, there is no way around looking at specific questions that come to the fore for such data. Internal to a GIS, for example, there is the need to consider topological and ontological questions or issues. Topology means a geometric configuration of data which leads one to be constrained by maintaining data structures that are geographic. Lines should match lines, and they must be joined by nodes; analysis cannot take place if features and entities do not correspond to the reality one is trying to describe or analyze. Topology is maintained inside the geospatial data and is a product of how the data was created. The information manager's goal is to (a) make sure topology is kept and (b) find problems that may exist and fix them. Without topology, geospatial data is just numbers with no context. An additional geospatial information consideration is with regard to the ontologies of the databases. Without being able to classify fields within the data, any geomatics technology will be unable to determine such basics as ' $x=$ longitude'. It may seem simple, but all too often such questions of topology and ontology are given only a cursory review (Fabrikant, \& Buttenfield, 2001).

Two things always arise when a project begins that utilizes geospatial information: what is the source of the data and how is it described? For example, data may arrive with a defined map and assume that a GIS facilitator will recognize this map projection. Such technicalities cannot 
be assumed. The user must have access to some kind of metadata which describes the method of creation and the end result, be that the projection of some other feature.

The next important consideration is with regard to project management. Just as topology is required as a means to an end - making sure data matches reality and internal structures there is also the need to keep data where it 'needs' to be kept. Having databases located in many folders is a very inefficient way to mange a project. In fact, such a process can actually impede the ability of the GIS to create a project. Keeping all data, and all projects, in a relational database, along with other data sources such as numeric census data means that the GIS can be more effective and projects do not get 'lost'; not to mention the issues of archiving (Jacobs \& Humphrey, 2004; Ross, 2000).

In addition, data structures must be managed carefully because processing ability and power decreases proportionally with poor organization. All these, and more, create an environment where spatial technologies and spatial information make spatial a special form of information management and application.

\section{Policies}

Policies, issues and trends, environmental drivers, social forces, information issues such as access, pricing, copyright, privacy, security and education, and technical infrastructures (if you notice it, it failed) are some of the items that must be considered in any discussion of geospatial information. A myriad of questions grow out of trying to solve the above (you may build it, but you can't sustain it; who archives the information? what about digital divide?), some of which will be answered herein, while others deserve much more attention on their own. The key policy areas of interest to the geospatial information community are presented below: pricing, copyright, security, privacy, licensing, and access and use.

Now that we have laid the groundwork and background of geospatial information, and the broad framework for the paper, that being policy and management, it is instructive to review some of the specific issues that affect management of geospatial information. These issues are the precursors to information access and use. There are specific information management questions that arise from the use of geospatial information, but these are left to a later part of this discussion. Yet, we must or should keep in mind that there are other forces at play which can influence the direction of policy (Borgman, 2003).

\section{Pricing}

Probably the first and most important consideration in geospatial information policy is that of pricing. There is a relationship between price and copyright, especially in nations which have 
copyright laws governing governmental data. In the United States, the federal government does not hold copyright on materials produced by federal agencies with taxpayers' dollars. Therefore, a situation develops where both the public and private sector can create valueadded products within the fear of being charged with copyright infringement. Furthermore, US Code, Title 44 states that government information will be distributed at no more than the cost of reproducing the information. This combination creates a market where users of geospatial information can acquire that data with little effort (in terms of price). These policies have created a very strong marketplace (Lopez, 2004).

Price in Canada has been an issue for a long time (Klinkenberg, B. 2003). Governmental pricing, with governments holding the vast majority of data, has been a varied situation across the land with some provinces charging full cost and others providing free access. At the present time there are projects underway to allow for free distribution in the hope that a more active industry will grow. Pricing is not the only factor which has been a barrier to improved access. As we shall see, because Canada lacks a Title 44, and a constitution allowing for governmental copyright, access is rather different and the information manager must be aware of these issues.

\section{Copyright}

While there is not federal copyright in the US, Canadian geospatial information is 'controlled' by Crown Copyright. Such a policy means, in specific terms, each product generated using federal geospatial information must cite the source and provide a statement attributing the data to the Crown. Not doing so means that the information manager, which we assume is the custodian of the data obtained via a federal source, will run the risk of losing access to that data. This situation is changing quickly, and in keeping with recent studies regarding the impact of both pricing and copyright (Sears, 2001).

\section{Security}

We face a certain loss of access to data because of changing views related to such access (Onsrud, 1998b). With the events of September 11, 2001 there have been more efforts to decrease access to information that is deemed to be 'sensitive' or potentially dangerous if made widely available. Geospatial information is perhaps the most susceptible to new restrictions because of the power one has to combine geospatial information with other sources. Simply finding the location of a power plant, airport runway, building or other site that could come under attack is part and parcel some of the spatial elements in geospatial databases. 
Add into this mix the ability to combine this with global positioning systems - those used in missiles, and it is easy to see way such data is more and more coming under closer scrutiny. This is an issue that managers should be aware of; there have been cases where information has been requested to be destroyed or withdrawn from the public domain (see Pinkser, 2003). Security was not always a concern of information managers, except perhaps for hackers and the like. To not be aware of this policy issue is to not be aware of current issues in information management.

\section{Privacy}

An additional policy issue is not new to those information services professions is that of privacy. In geospatial information management the issue boils down to one of location and identification. If a GIS, for example, is combined with census data, it is possible to come to know a very small area and determine the 'traits' of that place, say income for example. However, with more precise data like shopping patterns or video rental preferences, it is possible to 'profile' someone based upon their location. The power of databases, of all sorts, is increased greatly when some element of that source is combined with locational information. How many times are we asked for our postal code when we buy something? (Say 'no' if you don't want to have your location tracked by a database that later gets shared among several companies.)

Also, with the advent of international trans-border data flows (Longworth, 2001; Regan, 2003) we have seen an increased awareness on the part of governments that there are implication for such movement of data. Geospatial information can easily be attached to that data; most of those who generate data today add in a geospatial component (Hernon and Duncan, 1997).

\section{Licensing}

The example that pops to mind is the normal clause in all data licenses which sates, in rough form, "the user will not lend, lease, deliver or otherwise distribute the data for value added purposes to any third party without the express written permission of the data provider." This poses several problems for students and researchers. First, a user will develop a value added product - the research and resulting publications, such as a thesis of paper. Second, there are, at times, partners involved in a student project (via funding or by results returning to the supporter). This often happens when students are working closely with a non-profit group. However, these are by no means the only issues (NRC, 2004).

There is also the matter of who licenses the data. Students and researchers should not be asked to sign licenses which will bind them to an agreement that does not allow for a wide 
range of activities. Student work that results in a thesis can be hampered by restrictions in the license. This is where the information professional can come into the situation as a neutral broker. Data providers are more likely willing to deal with one person or agency, such as a library, that can enforce or monitor the agreement. While this is not necessarily a position many in libraries would want to be put into, there are benefits which can accrue to other potential users. A savvy licensee can broker a license that allows for user and distribution to more than the original requestor. The result is that the licensee becomes the data manager and should be able to foster a better and more collegial relationship with data suppliers. Word of mouth regarding secure access and license monitoring can go a long way in developing positive relationships with other agencies.

\section{Educational access and use}

The culmination of these policy issues in the context of geospatial information is the question of access, and the assumed end result of use. There is seen, from a world-view, a benefit to access as wide as possible (Global Information Infrastructure Commission, (n.d.); OECD, 2003). Questions of copyright and pricing have a direct bearing on access, as do the questions of security and licensing, but the issue of access and use goes beyond any one of those concerns. Geospatial information is so vital to geomatics and spatial analysis that it has gained a place in the literature (Craglia, \& Masser, 2001; Wehn de Montalvo, 2002).

Use can not take place before access, and access requires other policy questions to be answered. One key goal (or is that "role"?), for the information manager is to deal with the question of access first - turning the equation on its head. We can make the case for access and then find ways to deal with or negotiate the other questions. This forces us to think about and justify a position of open access and free use. It matters not on which side of the fence one resides - data provider or data requester - starting from the premise of open access then creates a dynamic for more open and critical evaluation of policies that may run against that view (see: Kahle, Jackson., \& Prelinger. 2001; and Sullivan, \& Dilek, 1997).

\section{PPGIS as an answer?}

One of the more innovative approaches to access and use, has been the move towards public participatory GIS (PPGIS). As the name implies, PPGIS is geared to use of the technologies by a wider audience than just the 'experts' (Kyem, 2000). PPGIS must, by the nature of GIS, rely upon the availability of geospatial information, be that provided to a 'community' or generated from within (Harris and Weiner, 1998). PPGIS demands open access to information, and as such, it may well provide a basis by which information managers can approach data access issues. Using a PPGIS project may entitle a manager to more information. This entails having the project as a collaborative enterprise with users and producers working together 
(Carver, 2003). This sort of process goes against the standard or historical aspects of access and use, although the authors readily agree that the landscape has changed significantly. However, it is best if change has a direction and philosophy, which PPGIS provides. This is not counter to any other change which is taking place in the geospatial information community. In fact, there have been substantial calls for more approaches that combine the theory, GIScience, with approaches from a wide array of fields (Goodchild, 2000a). Such change is not unexpected or unplanned for in the information community (Millea, 2001).

\section{Spatial Data Infrastructures}

Following from PPGIS is another area of GIScience that deserves attention for its foundation in policy change is SDI's. A clear connection between SDI's and information managers exists because the structure and implementation of these new 'spatial data infrastructures' are based upon information management and information policy principles (Groot \& McLaughlin, 2000). From the information professional's point of view, these spatial information networks are not dissimilar to digital libraries; only the content is different between the two digital networks (Boxall, 2002; Reid, Higgins, Medyckyj-Scott, \& Robson, 2004). Issues inherent in managing infrastructures are only apparent when they affect a user directly. We only notice the phone or power infrastructure when it is not working; how many of us have thought about where the water is coming from and where it is going when we showered? The goal of those developing geospatial information infrastructures is to make them (a) pervasive and (b) unseen (GSDI, 2004; OECD, 1997).

Spatial information infrastructures are digital libraries (Mapping Science Committee, 1999), but the trend is towards a more global system (Yarbrough, 2001). For the information professional, the notion of such libraries and/or infrastructure is best exemplified by the idea of the geolibrary (Boxall, 2004). Not only data, but services can be offered through the Geolibrary (Mapping Science Committee, 1999). The implications are grand; policy and practices for services must be at the fore in any implementation of such data access processes. The opportunities to interact with such networks provide both a very exciting opportunity and a daunting task. If how geospatial information has come to be part of the information management field, then there is every reason that in a decade hence we will see the information professional, in or outside libraries, at the forefront of such change.

\section{Why is spatial still special?}

Because the vast majority of information is spatial, and of that geospatial data is of the greatest proportion, it follows that geospatial information management - especially from a policy perspective - deserves much attention by information managers. The ubiquitous nature of information technology in various parts of the world means that people have fairly easy access 
to the tools in order to use geospatial information. Furthermore, geospatial information is becoming so widely available that even if the technology lags a little behind, a global awareness of its presence is inevitable. More people are becoming comfortable with spatially based services (e.g. LBS, eMaps in cars, MapQuest, palms/PDA's with GPS, and cellular phones) and this serves to propagate the geospatial phenomenon.

Spatial is building upon our innate appreciation for 'place' and it is that which makes spatial so special. In fact, spatial is so commonplace and inherent in what we do that that it could be suggested that it isn't so special at all. This would mean that success for those seeking a global spatial data infrastructure, a new goal should become transparency or invisibility of the infrastructure. The real driver in this area is not policy, access or use by researchers, it is the degree to which people value 'spatial'. Evidence of this is found in the formation of new management models and practices (Rhind, 2001) based upon geospatial information, and those are the driving forces.

The role of managers, regardless of discipline, should be to (a) keep abreast of developments and scope out trends, (b) become more literate in how to use the technology and data (this may mean listening to younger employees who are more savvy), (c) being well versed in the areas of pricing, licensing and information policy, and (d) accept that the speed of change will produce "unintended consequences" (see Tenner, 1996). Spatial industries are growing at $25 \%$ per year, and it is becoming more embedded in everyday life as a technology, data source, and tool. If it is not special, it is at a minimum critical and pervasive. Libraries are at the forefront of these developments, hopefully reacting and changing shape in response to a new demand. Regardless, sitting on the fence is no longer an option (Buttenfield, 1998).

\section{Conclusion}

We are seeing massive and continuous change in the information marketplace, not just in terms of data, but in relation to changes in technology. Tangible devices are becoming disposable; it is often cheaper to throw away and replace than it is to fix. Such technical wastefulness in society has been criticized (Rozak, 1994; Tenner, 1996). Conversely, the nature of information is such that we cannot do without it. The continuum of information in society supposedly provides us with knowledge and wisdom. This has been as true today as it has been in the past. Aristotle once said "If you would understand anything, observe its beginning and its development." One need only to examine our historic use of geospatial information to understand how dependent humans have become in understanding space and time and how this ambition will persist in the future (see Brown and Duguid, 2000 for a thorough examination of information's role in our lives, past, present and future). 
And a word or two about where geospatial libraries will be in the near future, taking the trends outlined in this paper. Al Gore, the former Vice President of the United States, presented the geospatial community with a vision, one which was also a challenge that would see the development of a global information society called "digital earth." DE, as it has come to be known, would be the ultimate spatial data infrastructure - all information with a spatial component would be accessible and viewable as a series of themes on the same platform or the screen (head mounted or on the wall) (Gore, 1998). This is a massive undertaking that would require a tremendous amount of power and innovation within the disciplines of information management. Such a system also implies an answer to all information policies (Goodchild, 2000b). But this is not beyond the realm of possibilities, and it is very much in keeping with what technologists are doing in tandem with the principles of information managers (Robinson, \& Bawden, 2001).

This should be an age of wonderment and celebration of what information can do for us, beyond an information economy (Evans, 2001). We must find positive uses of geospatial information, such as those offered through the PPGIS paradigm, and in support of effective environmental management. Information policies associated with geospatial information, those that were briefly touched upon in this paper, are at the crux of any further development of infrastructures through which geospatial information emerges. The unique nature of geospatial information and widespread application of geomatics technologies means that geospatial information should be viewed differently by information managers and recognized as a unique area of study - spatial is still special. 


\section{Reference}

ARL. (1997). Transforming Libraries: Issues and Innovations in Geographic Information Systems," Transforming Libraries, No. 2 February 1997 (ARL SPEC Kit 219), George Soete (ed.) Washington, D.C.: ARL. Retrieved April 10, 2004, from http://www.arl.org/transform/ gis/gistrans.html.

Benkler, Y. (2003). Freedom in the commons: towards a political economy of information. 52 Duke Law Journal, 1245. Retrieved October 3, 2004, from http://www.benkler.org/Pub.html [1]

Birdsall, W. F. (2000). A political economy of librarianship? Hermes: revue critique, 6. Retrieved June 10, 2003, from http://pages.globetrotter.net/charro/HERMES6/ birdsall.htm.

Borgman, C. L. (2003). Personal Digital Libraries: Creating Individual Spaces for Innovation. Working Paper, National Science Foundation Post Digital Libraries Workshop. June 15-17 2003, Chatham, Massachusetts.

Boxall, J. C. (2004). Advances and trends in geospatial information accessibility - Part I: Geolibraries. Journal of Map \& Geography Libraries, 1(1), 7-39.

Boxall, J.C. (2003). Geolibraries: Geographers, Librarians and Spatial Collaboration. Canadian Geographer, 47,(1): 18-27. Retrieved March 1, 2004, from http://www.blackwellsynergy.com/links/doi/10.1111/1541-0064.02e09/full/.

Boxall. J.C. (2002). Geolibraries, the Global Spatial Data Infrastructure and Digital Earth: a time for map librarians to reflect upon the Moonshot. INSPEL (Journal of the International Federation of Library Associations) 36,(1): 1-21 Retrieved June 14th 2003, from http://www.ifla.org/lV/ifla67/papers/130-166e.pdf.

Brown, J. S., \& Duguid, P. (2000). The Social Life of Information. Boston: Harvard Business School Press.

Browne, M. (1997a). The field of information policy: 1. Fundamental concepts. Journal of Information science, 23(4), 261 -275.

Browne, M. (1997b). The field of information policy: 2. Redefining the boundaries and methodologies. Journal of Information Science, 23(5), 339-351.

Buttenfield, Barbara P. (1998). Looking Forward: Geogrpahic Information Services and Libraries in the Future. Cartography and Geographic Information Systems Special Issue. 
Spatial Information Infrastructures in the 1990s, James Boxall (Ed). July1998. 25(3): 129-131.

Cline, N. M. and P.S. Adler. (1995). GIS and Research Libraries: One Perspective. Information Technology and Libraries, 14,(2): 111-115.

Cobb, D. A. (1995). Developing GIS Relationships. Journal of Academic Librarianship 21,(4): 275-277.

Carver, S. (2003). The future of participatory approaches using geographic information: Developing a research agenda for the 21st century. URISA Journal, 15(1). Retrieved September 12, 2004, from http://www.urisa.org./Journal/ APANo1/ JrnIContents15-APA1.htm.

Craglia, M. \& Masser, I. (2001) Access to geographic information: a European perspective. A Position paper for the ESFNSF Workshop on Access to geographic Information and Participatory Approaches using geographic Information, Spoleto Italy, 6-8 December, 2001. Retrieved March 1, 2004, from * * http://www.shef.ac.uk/ scgisa/spoleto/craglia.pdf [2] .

Evans, Lord (2001) The Economy of the Imagination: The New Statesman Arts Lecture, June 27th, 2001 [www.resource.gov.uk/information/newstat01.html].

Fabrikant S.I. \& Buttenfield B.P. (2001). Formalizing Semantic Spaces for Information Access Annals of the Association of American Geographers, 91(2), 263-280.

Fleet, C. 1998. The Role of Computer Technology in the Future Map Library. LIBER Quarterly 8(2) <Accessed June 13th 2003: http://www.konbib.nl/kb/skd/liber/articles/>.

Hernon, P. and R. Duncan, 1997, GIS and Privacy. Journal of Academic Librarianship, 23(6), 515.

Georgiadou, Y. \& Groot R. (2002). Policy development and capacity building for geoinformation provision. GIS Development July 2002. Retrieved March 12, 2004, from http://www.gisdevelopment.net/magazine/gisdev/2002/jul/pdcbgp.shtml.

Global Information Infrastructure Commission. (n.d.). Rights in information access and use: Guiding Principles. Retrieved March 10, 2004, from http://www.giic.org/pubs/pgiirightsipr.asp.

Goodchild, M. F. (2000a). New horizons for the social sciences: Geographical information systems. Canadian Journal of Policy Research, 1(1), 158-161. 
Goodchild, M. F. (2000b). Cartographic perspectives on a digital future, Cartographic Perspectives, 36, 1-9.

Goodchild, M. F. (1998). The geolibrary. In S.Carver (Ed.), Innovations in GIS 5 (pp.59-68). London: Taylor and Francis.

Gore, A. (1998). The digital earth: understanding our planet in the $21^{\text {st }}$ century. Remarks by the Vice President, given at the California Science Center, Los Angeles January 31, 1998.Retrieved January 19, 2000, from http://digitalearth.gsfc.nasa.gov/ VP19980131.html.

Groot, R., \& McLaughlin, J. (Eds.). (2000). Geospatial data infrastructure: concepts, cases and good practice. Oxford: Oxford University Press.

GSDI (2004). Global Spatial Data Infrastructure Newsletter, January 2004.

Harris, T. M., \& Weiner, D., (1998). Empowerment, marginalization, and 'community-integrated GIS. Cartography and Geographic Information System, 25: 67-76.

[IFLA] (n.,d.) Information Policy: Copyright and Intellectual Property. Retrieved March 1, 2004, from http://www.ifla.org/ll/cpyright.htm.

Jacobs, J.A., \& Humphrey, C. (2004). Preserving research data. Communications of the ACM, 47(9), 27-29.

Kahle, B., M.E. Jackson., R. Prelinger. (2001). Public Access to Digital Material. D-Lib Magazine 7, (10) Retrieved February 1, 2005, from http://www.dlib.org.

Klinkenberg, B. (2003). The True Cost of Spatial Data in Canada. Canadian Geographer, 47(1): 37-49.

Lopez, X. (2004) Government policy and the emergence of spatial information markets http://www.gisdevelopment.net/policy/international/.

Longworth, E. (2001, March). Transborder data flow: EU directive and implications for international business. Paper presented at the E-Privacy in the New Economy Conference, Hong Kong. Retrieved March 1, 2004, from http://www.pco.org.hk/english/infocentre/files/nz3.doc. 
Kyem, P. A. K. (2000). Embedding GIS applications into resource management and planning activities of local and indigenous communities: a desirable innovation or a destabilizing enterprise? Journal of Planning Education and Research 20(2), 176-186.

Mapping Science Committee. (1999). Distributed geolibraries: Spatial information resources. Summary of a workshop: Panel on distributed geolibraries, mapping science committee (National Research Council [US]). Washington, D.C.: National Academy Press. Retrieved February 10, 2002, from http://www.nap.edu/html/geolibraries/.

Millea, N. (2001) Organizational Change. In R.B.Parry and C.R.Perkins (eds.) The Map Library in the New Millennium. Chicago: ALA Editions (28-42).

National Research Council (NRC), (2004). Licensing Geographic Data and Services [Executive Summary]. Committee on Licensing Geographic Data and Services. Washington, DC: The National Academies Press.

[OECD]. (2003).Promoting access to public research data for scientific, economic, and social development. Follow Up Group on Issues of Access to Publicly Funded Research Data, Final Report, March 2003. Retrieved April 1, 2004, from http://dataaccess.ucsd.edu/ FinalReport2003.pdf.

OECD (1997). Towards a Global Information Society: Global Information Infrastructure - Global Information Society: Policy Requirements. Paris: Organisation for Economic Co-operation and Development.

Onsrud, H.J., (1998) The Tragedy of the Information Commons. In Taylor, F. (Ed.), Policy Issues in Modern Cartography (Oxford: Elsevier Science) 141-158.

Pinsker, L. M. (2003). Mapping Secure Boundaries for Data," Geotimes [Science after 9/11 series]. Retrieved April 12 2003, from http://www.geotimes/org/apr03/NNdata.html.

Regan, P.M. (2003). Safe harbors or free trade frontiers? privacy and transborder data flows [Electronic Version]. Journal of Social Issues, 59 (2), 263-282.

Reid, J., Higgins, C., Medyckyj-Scott, D., \& Robson, A. (2004). Spatial data infrastructures and digital libraries: Paths to covergence. D-Lib Magazine, 10(5).

Rhind, David W. (2001). Global and national Geographic Information policies, practice and education in a g-business world. In Proceedings of AGILE 2001 Brno, Czech Republic. Available : agile.uni-muenster.de/Conference/Brno2001/Opening.pdf. 
Robinson, L \& Bawden, D. (2001). Libraries and open society; Popper, Soros and digital information. Aslib Proceedings 53(5): 167-178.

Ross, S. (2000). Changing Trains at Wigan: Digital Preservation and the Future of Scholarship. London: National Preservation.Office. Retrieved April 1, 2004, from http://www.bl.uk/services/npo/occpaper.pdf.

Rowlands, I. ( 2003a). Knowledge production, consumption and impact: policy indicators for a changing world. Aslib Proceedings 55(1/2): 5-12.

Rowlands, I. (2003b). Information policy: Complexity, scope and normative structure. In S. Hornby, \& Z.Clarke (Eds.), Challenge and change in the information society (pp. 131-146). London: Facet Publishing.

Roszak, T. (1994). The cult of information: a neo-luddite treatise on high-tech, artificial intelligence, and the true art of thinking. Berkeley, CA: University of California Press c1994.

Sears, G. (2001). Geospatial data policy study [Executive Summary] By KPMG Consulting Inc. for GeoConnections Policy Node (GeoConnections Secretariat, Natural Resources Canada) Retrieved January, 2003, from http://www.geoconnections.org.

Sullivan, M.A., Dilek, Y. (1997). Enhancing Scientific Literacy Through the Use of Information Technology in Introductory GeoScience ClassesJournal of Geoscience Education 45: 308-313.

Tenner, E. 1996. Why things bite back: technology and the revenge of unintended consequences. New York: Knopf.

Wehn de Montalvo, U. 2002, To share or not to share Attitudes and mindsets vis-à-vis spatial data, GIS Development. Retrieved March 1, 2004, from http://www.gisdevelopment.net/magazine/gisdev/2002/jul/tsns.shtml.

Yarbrough, T.L. (2001). Connecting the world: the development of the global information infrastructure. Federal Communications Law Journal, 53 (2), 315- 341. 